\title{
PENGARUH MEDIA DAN NAUNGAN TERHADAP MUTU BIBIT SUREN (Toona sureni MERR.)
}

\author{
The Effect of Media and Shading on the Seedling's Quality of Suren \\ (Toona sureni Merr.)
}

\author{
Rina Kurniaty, Budi Budiman dan/and Made Suartana \\ Balai Penelitian Teknologi Perbenihan Bogor \\ Jl. Pakuan Ciheuleut Po. Box 105, Bogor 16801 \\ Telp./Fax. (0251) 8327768
}

Naskah masuk : 23 Maret 2009 ; Naskah diterima : 4 Maret 2010

\begin{abstract}
Seedling quality is one of determining factors for successful forest establishment and land rehabilitation programs, as good quality seedlings will yield tree with high productivity level. Media which have high content of organic matter and plant nutrients are reguired seedling growth. Generally, top soil is used for seedling growing medium. However, such practice is inappropriate due to its adverse effect to the ecosystem. A substitute is therefore needed.In this study, soil, coconut husk, or combination of the two were evaluated as growing medium, either alone or being combined with rice husk. The different components in a medium were set at equal proportion. Seedlings were grown eitherwith shading at $40 \%$ or $70 \%$ or none at all. The experiment was arranged in Completely Randomized Design with ten replicates consisting of 10 seedlings per replicate. The result showed that soil + coconut husk +rice husk (A6) with 40\% shading (B2) gave the best growth for 5 month suren's seedling that have $2.97 \mathrm{~mm}$ of diameter, $25.1 \mathrm{~cm}$ of height, $94.0 \%$ survival rate and 0.12 of quality index.
\end{abstract}

Key words : medium, shading, quaitly of seedling, suren

\begin{abstract}
ABSTRAK
Kualitas bibit tanaman sangat berpengaruh terhadap keberhasilan program pembangunan hutan tanaman dan rehabilitasi lahan bekas tebangan, karena bibit yang berkualitas akan menghasilkan tegakan dengan tingkat produktivitas tinggi. Untuk menghasilkan bibit berkualitas diantaranya diperlukan media yang kaya bahan organik dan mempunyai unsur hara yang diperlukan. Umumnya media yang digunakan adalah top soil, namun pengambilan top soil dalam skala besar dapat berdampak negatif bagi ekosistem di areal tersebut. Oleh karena itu penggunaan bahan lain untuk media pembibitan perlu dilakukan. Dalam penelitian ini digunakan 6 macam media yaitu tanah, sabut kelapa, dan kombinasinya serta campuran tiga media tersebut dengan arang sekam padi pada jenis tanaman suren. Rancangan yang digunakan adalah Rancangan Acak Lengkap dengan pola perhitungan faktorial terdiri dari 10 ulangan masing- masing 10 bibit. Hasil yang diperoleh menunjukkan bahwa media tanah + sabut kelapa + arang sekam dengan naungan $40 \%$ memberikan pertumbuhan terbaik untuk bibit suren umur 5 bulan yaitu diameter $2,97 \mathrm{~mm}$, tinggi 25,1 cm, persen hidup 94,0\% dan Indeks Mutu Bibit 0,12.
\end{abstract}

Kata kunci : media, naungan, mutu bibit, suren 


\section{PENDAHULUAN}

Kualitas bibit tanaman sangat berpengaruh terhadap keberhasilan program pembangunan hutan tanaman dan rehabilitasi lahan bekas tebangan, karena bibit yang berkualitas akan menghasilkan tegakan dengan tingkat produktivitas tinggi. Untuk menghasilkan bibit yang berkualitas diantaranya diperlukan media yang kaya dengan bahan organik dan mempunyai unsur hara yang diperlukan tanaman (Durahim dan Hendromono, 2001). Umumnya media yang digunakan untuk pembibitan di persemain berasal dari top soil. Namun pengambilan top soil dalam skala besar dapat berdampak negatif bagi ekosistem di areal tersebut (Hendromono, 1994). Oleh karena itu penggunaan bahan lain untuk media pertumbuhan bibit perlu dilakukan.

Hendromono dan Durahim (2004) melaporkan bahwa kompos sabut kelapa sawit + sekam padi $1: 1(\mathrm{~V}: \mathrm{V})$ merupakan media yang sesuai untuk pembibitan Khaya antotheca. Sementara Durahim dan Hendromono (2001) menyimpulkan bahwa penggunaan media campuran top-soil + sekam padi + sabut kelapa sawit 1:1:1 (V:V:V) meningkatkan pertumbuhan dan mutu morfologi bibit mahoni (Swietenia macrophylla).

Alrasyid et al. (2000) mengemukakan bahwa proses fotosintesis dan metabolisme suatu tanaman dipengaruhi oleh faktor luar seperti sinar matahari, tersedianya air, hara mineral dan kondisi tempat tumbuh. Intensitas cahaya terlalu rendah atau terlalu tinggi akan menghambat pertumbuhan tinggi tanaman (Sastrawinata, 1984). Intensitas cahaya yang terlalu rendah akan menghasilkan produk fotosintesis yang tidak maksimal, sedangkan intensitas cahaya yang terlalu tinggi akan berpengaruh terhadap aktivitas sel-sel stomata daun dalam mengurangi transpirasi sehingga mengakibatkan terhambatnya pertumbuhan tanaman.

Dalam rangka menunjang pengembangan hutan rakyat jenis suren (Toona sureni Merr.) maka dilakukan penelitian tentang pengaruh media dan naungan terhadap mutu bibit jenis suren. Tujuan penelitian untuk memperoleh bibit suren bermutu tinggi dengan menggunakan media selain tanah.

\section{METODE PENELITIAN}

\section{A. Lokasi dan Waktu Penelitian}

Penelitian dilakukan di laboratorium, rumah kaca (green house) dan kebun percobaan Nagrak, Balai Penelitian Teknologi Perbenihan Bogor dari bulan Februari sampai dengan Juni 2006.

\section{B. Bahan dan Alat}

Bahan dan alat yang digunakan dalam kegiatan ini adalah benih suren, ayakan pasir, tampah, bak kecambah, tanah, pasir, sabut kelapa, arang sekam padi, shading net ukuran $40 \%$ dan $75 \%$, polybag ukuran $14 \times 20 \mathrm{~cm}$, kaliper, lux meter, timbangan analitik, oven dan alat tulis.

\section{Metode Penelitian}

Pengunduhan dilakukan pada benih yang telah masak fisiologi dengan cara memanjat pohon atau perontokan sebagian dahan dengan menggunakan galah berkait. Buah yang sudah terkumpul kemudian dikemas dalam kantong plastik dan diberi label yang berisi lokasi dan tanggal pengunduhan serta tinggi dan diameter pohon.

Setelah benih terkumpul kemudian diekstraksi. Ekstraksi benih atau cara mengeluarkan benih dari buah untuk jenis suren adalah dengan dijemur sampai biji terlepas dari buahnya.

Perkecambahan dilakukan dengan menabur benih pada bak kecambah yang berisi media pasir + tanah 1: 1 (v:v) yang telah disterilkan. Setiap bak kecambah berisi 100 butir benih, sebanyak 20 bak.

Penyapihan dilakukan pada kecambah yang telah memiliki sepasang daun. Media yang digunakan adalah :

$$
\begin{aligned}
& \mathrm{A}_{1} \text { : tanah } \\
& \mathrm{A}_{2} \text { : sabut kelapa } \\
& \mathrm{A}_{3} \text { : arang sekam padi }+ \text { sabut kelapa } 1: 1(\mathrm{v}: \mathrm{v}) \\
& \mathrm{A}_{4} \text { : tanah }+ \text { sabut kelapa } 1: 1(\mathrm{v}: \mathrm{v}) \\
& \mathrm{A}_{5} \text { : tanah }+ \text { arang sekam padi } 1: 1(\mathrm{v}: \mathrm{v}) \\
& \mathrm{A}_{6}: \text { tanah }+ \text { sabut kelapa }+ \text { arang sekam padi } \\
& \quad 1: 1: 1(\mathrm{v}: \mathrm{v}: \mathrm{v})
\end{aligned}
$$

Bibit yang telah disapih dalam berbagai media tersebut diletakkan dalam bedengan 
dengan beberapa naungan yaitu :

$\mathrm{B}_{1}$ : naungan $0 \%$ (tanpa naungan),

$\mathrm{B}_{2}$ : naungan $40 \%$,

$\mathrm{B}_{3}$ : naungan $75 \%$.

Parameter yang diamati adalah tinggi, diameter batang dan dan persen hidup bibit, serta mutu bibit. Pengukuran tiga parameter tersebut dilakukan setiap bulan sampai bibit berumur 5 bulan setelah penyapihan. Untuk mengetahui kualitas bibit secara fisiologis, maka dilakukan penhitungan Indeks Mutu Bibit (IMB) dengan menggunakan cara Dickson (1960) dalam Hendromono (1994) dengan rumus :

Indeks Mutu: $\frac{\text { bobot kering batang }(\mathrm{gr})+\text { bobot kering akar }(\mathrm{gr})}{\frac{\text { tinggi }(\mathrm{cm})}{\text { diameter }(\mathrm{mm})}+\frac{\text { bobot kering batang }(\mathrm{gr})}{\text { bobot kering akar }(\mathrm{gr})}}$

Sebagai data pendukung dilakukan pengamatan analisis contoh media yang digunakan .

\section{Rancangan Penelitian}

Rancangan yang digunakan dalam penelitian ini adalah Rancangan Acak Lengkap dalam Faktorial dengan dua faktor yaitu A : Media dan B : Naungan. Masing-masing kombinasi perlakuan diulang sebanyak 10 kali dengan masing-masing ulangan 10 bibit, sehingga diperoleh 1800 satuan percobaan.

Untuk mengetahui perbedaan antar perlakuan, digunakan uji beda nyata Duncan (Duncan Multiple Range Test) terhadap nilai tengah masing-masing tolok ukur pengamatan.

\section{HASIL DAN PEMBAHASAN}

\section{A. Hasil Penelitian}

\section{Tinggi Bibit}

Rata-rata pertumbuhan tinggi bibit suren selama 5 bulan disajikan pada Tabel 1 berikut ini :

Tabel (Table) 1. Pertumbuhan tinggi bibit suren selama 5 bulan (The height growth of suren's seedling during 5 months)

\begin{tabular}{|c|r|r|r|r|c|}
\hline \multirow{2}{*}{$\begin{array}{c}\text { Perlakuan } \\
\text { (Treatment })\end{array}$} & \multicolumn{5}{|c|}{ Bulan ke (Month) } \\
\cline { 2 - 6 } & 1 & 2 & 3 & 4 & 5 \\
\hline $\mathrm{A}_{1} \mathrm{~B}_{1}$ & 17,52 & 10,86 & 7,66 & 6,07 & 3,55 \\
\hline $\mathrm{A}_{1} \mathrm{~B}_{2}$ & 16,12 & 13,51 & 11,69 & 8,34 & 4,62 \\
\hline $\mathrm{A}_{1} \mathrm{~B}_{3}$ & 21,95 & 14,67 & 11,27 & 9,09 & 6,50 \\
\hline $\mathrm{A}_{2} \mathrm{~B}_{1}$ & 8,95 & 6,27 & 4,52 & 4,20 & 3,23 \\
\hline $\mathrm{A}_{2} \mathrm{~B}_{2}$ & 7,32 & 5,83 & 4,46 & 4,05 & 3,15 \\
\hline $\mathrm{A}_{2} \mathrm{~B}_{3}$ & 6,38 & 5,48 & 4,58 & 4,16 & 4,29 \\
\hline $\mathrm{A}_{3} \mathrm{~B}_{1}$ & 5,00 & 0,40 & 3,78 & 3,61 & 2,70 \\
\hline $\mathrm{A}_{3} \mathrm{~B}_{2}$ & 8,75 & 6,99 & 5,53 & 4,58 & 3,54 \\
\hline $\mathrm{A}_{3} \mathrm{~B}_{3}$ & 7,95 & 5,95 & 4,52 & 1,96 & 3,67 \\
\hline $\mathrm{A}_{4} \mathrm{~B}_{1}$ & 8,95 & 6,50 & 4,85 & 4,31 & 2,99 \\
\hline $\mathrm{A}_{4} \mathrm{~B}_{2}$ & 9,30 & 6,95 & 5,57 & 4,84 & 3,36 \\
\hline $\mathrm{A}_{4} \mathrm{~B}_{3}$ & 12,50 & 8,91 & 6,89 & 4,89 & 4,33 \\
\hline $\mathrm{A}_{5} \mathrm{~B}_{1}$ & 17,64 & 12,09 & 9,82 & 7,81 & 5,30 \\
\hline $\mathrm{A}_{5} \mathrm{~B}_{2}$ & 21,56 & 14,61 & 10,93 & 8,92 & 4,93 \\
\hline $\mathrm{A}_{5} \mathrm{~B}_{3}$ & 21,25 & 15,51 & 12,24 & 9,25 & 6,04 \\
\hline $\mathrm{A}_{6} \mathrm{~B}_{1}$ & 17,26 & 10,38 & 8,04 & 6,47 & 3,57 \\
\hline $\mathrm{A}_{6} \mathrm{~B}_{2}$ & 25,14 & 15,76 & 10,51 & 7,36 & 4,07 \\
\hline $\mathrm{A}_{6} \mathrm{~B}_{3}$ & 12,88 & 9,00 & 7,08 & 5,47 & 3,96 \\
\hline & & & & \\
\hline
\end{tabular}

Berdasarkan Tabel 1 diatas dapat dilihat bahwa perlakuan media : tanah + sabut kelapa + arang sekam padi $1: 1: 1$ (v:v:v) pada naungan $40 \%\left(\mathrm{~A}_{6} \mathrm{~B}_{2}\right)$ memiliki rata-rata pertumbuhan tinggi terbaik, yaitu 4,07 $\mathrm{cm}$ pada umur 1 bulan, meningkat menjadi $25,14 \mathrm{~cm}$ pada umur 5 bulan. Sedangkan perlakuan media arang sekam padi + sabut kelapa (1:1) pada naungan $0 \%\left(\mathrm{~A}_{3} \mathrm{~B}_{1}\right)$ 
memiliki rata-rata pertumbuhan tinggi terendah yaitu $2,70 \mathrm{~cm}$ pada umur 1 bulan dan hanya mencapai $5,00 \mathrm{~cm}$ pada umur 5 bulan.

Hasil analisis keragaman pengaruh media dan naungan terhadap pertumbuhan tinggi bibit suren umur 5 bulan (Lampiran 1) menunjukkan bahwa perbedaan media serta kombinasi media dan naungan menunjukkan pengaruh yang nyata pada taraf $1 \%$, sedangkan perbedaan naungan tidak menunjukkan pengaruh yang nyata.

Hasil uji beda nyata Duncan pengaruh media dan naungan terhadap pertumbuhan tinggi (Lampiran 3) menunjukkan bahwa bibit yang ditanam dalam media tanah + arang sekam padi + sabut kelapa (1:1:1) pada naungan 40\% $\left(\mathrm{A}_{6} \mathrm{~B}_{2}\right)$ memiliki rata-rata tinggi bibit terbaik $(25,14 \mathrm{~cm})$ yang tidak berbeda nyata dengan perlakuan $\mathrm{A}_{5} \mathrm{~B}_{2}$ dan $\mathrm{A}_{5} \mathrm{~B}_{3}$. Sedangkan bibit yang ditanam dalam media sabut kelapa + arang sekam padi (1:1) pada naungan $0 \%\left(\mathrm{~A}_{3} \mathrm{~B}_{1}\right)$ memiliki rata-rata tinggi terendah $(5 \mathrm{~cm})$ yang tidak berbeda nyata dengan tujuh perlakuan lainnya.

\section{Diameter Bibit}

Rata-rata pertumbuhan diameter bibit suren selama 5 bulan disajikan pada Tabel 2 berikut ini :

Tabel (Table) 2. Grafik pertumbuhan diameter bibit suren selama 5 bulan (The diameter growth of suren's seedling during 5 months)

\begin{tabular}{|c|c|c|c|c|c|}
\hline \multirow{2}{*}{$\begin{array}{c}\text { Perlakuan } \\
\text { (Treatment) }\end{array}$} & \multicolumn{5}{|c|}{ Bulan ke (Month) } \\
\cline { 2 - 6 } & 5 & 4 & 3 & 2 & 1 \\
\hline $\mathrm{A}_{1} \mathrm{~B}_{1}$ & 2.62 & 2,14 & 1,41 & 1,15 & 0,26 \\
\hline $\mathrm{A}_{1} \mathrm{~B}_{2}$ & 2,02 & 1,82 & 1,31 & 1,10 & 0,71 \\
\hline $\mathrm{A}_{1} \mathrm{~B}_{3}$ & 2,75 & 2,17 & 1,53 & 1,00 & 0,70 \\
\hline $\mathrm{A}_{2} \mathrm{~B}_{1}$ & 1,52 & 1,20 & 0,96 & 0,72 & 0,54 \\
\hline $\mathrm{A}_{2} \mathrm{~B}_{2}$ & 1,62 & 1,25 & 0,92 & 0,74 & 0,55 \\
\hline $\mathrm{A}_{2} \mathrm{~B}_{3}$ & 1,36 & 1,10 & 0,80 & 0,85 & 0,52 \\
\hline $\mathrm{A}_{3} \mathrm{~B}_{1}$ & 0,80 & 0,24 & 0,61 & 0,56 & 0,47 \\
\hline $\mathrm{A}_{3} \mathrm{~B}_{2}$ & 1,85 & 1,31 & 0,94 & 0,72 & 0,54 \\
\hline $\mathrm{A}_{3} \mathrm{~B}_{3}$ & 1,62 & 1,31 & 0,98 & 0,70 & 0,51 \\
\hline $\mathrm{A}_{4} \mathrm{~B}_{1}$ & 1,43 & 1,21 & 0,97 & 0,60 & 0,52 \\
\hline $\mathrm{A}_{4} \mathrm{~B}_{2}$ & 1,82 & 1,51 & 1,16 & 0,78 & 0,55 \\
\hline $\mathrm{A}_{4} \mathrm{~B}_{3}$ & 2,26 & 1,80 & 1,12 & 0,92 & 0,62 \\
\hline $\mathrm{A}_{5} \mathrm{~B}_{1}$ & 3,01 & 2,15 & 1,73 & 1,19 & 0,82 \\
\hline $\mathrm{A}_{5} \mathrm{~B}_{2}$ & 2,57 & 2,07 & 1,50 & 1,07 & 0,63 \\
\hline $\mathrm{A}_{5} \mathrm{~B}_{3}$ & 2,83 & 2,25 & 1,68 & 1,21 & 0,77 \\
\hline $\mathrm{A}_{6} \mathrm{~B}_{1}$ & 2,77 & 2,20 & 1,70 & 1,11 & 0,67 \\
\hline $\mathrm{A}_{6} \mathrm{~B}_{2}$ & 2,97 & 2,27 & 1,70 & 1,18 & 0,60 \\
\hline $\mathrm{A}_{6} \mathrm{~B}_{3}$ & 2,22 & 1,63 & 1,23 & 0,88 & 0,55 \\
\hline
\end{tabular}

Berdasarkan Tabel 2 diatas dapat dilihat bahwa perlakuan media tanah + arang sekam padi (1:1) pada naungan $0 \%\left(\mathrm{~A}_{5} \mathrm{~B}_{1}\right)$ memiliki rata-rata pertumbuhan diameter terbaik yaitu $0,82 \mathrm{~mm}$ pada umur 1 bulan meningkat menjadi $3,01 \mathrm{~mm}$ pada akhir periode pengamatan (5 bulan). Sedangkan perlakuan media Arang sekam padi + Sabut kelapa(1:1) pada naungan $0 \% \quad\left(\mathrm{~A}_{3} \mathrm{~B}_{1}\right)$ memiliki rata-rata pertumbuhan diameter terendah yaitu $0,47 \mathrm{~mm}$ pada umur 1 bulan dan hanya mencapai $0,80 \mathrm{~mm}$ pada akhir periode pengamatan ( 5 bulan).

Hasil analisis keragaman pengaruh media dan naungan terhadap pertumbuhan diameter bibit suren umur 5 bulan (Lampiran 1) menunjukkan bahwa perbedaan media serta kombinasi media dan naungan menunjukkan pengaruh yang nyata sedangkan perbedaan naungan tidak memberikan pengaruh yang nyata. Hasil uji beda nyata Duncan pengaruh media dan naungan terhadap pertumbuhan diameter bibit suren (Lampiran 3) menunjukkan bahwa bibit 
yang ditanam dalam tanah + arang sekam padi (1:1) tanpa dinaungi $\left(\mathrm{A}_{5} \mathrm{~B}_{1}\right)$ memiliki rata-rata diameter terbaik $(3,00 \mathrm{~mm})$ yang tidak berbeda nyata dengan bibit yang ditanam dalam media tanah + arang sekam padi + sabut kelapa $(1: 1: 1)$ $\left(A_{6}\right)$ pada naungan $40 \%\left(A_{6} B_{2}\right)$. Sedangkan bibit suren yang ditanam dalam media arang sekam padi + sabut kelapa (1:1) tanpa dinaungi $\left(\mathrm{A}_{3} \mathrm{~B}_{1}\right)$ memiliki rata-rata diameter terendah $(0,08 \mathrm{~mm})$.

\section{Persen Hidup Bibit}

Rata-rata persen hidup bibit suren sampai dengan umur 5 bulan disajikan pada Tabel 3 berikut ini :

Tabel(Table) 3. Persen hidup bibit suren umur 5 bulan (The survival rate of suren's seedling at 5 months age)

\begin{tabular}{|l|c|c|c|}
\hline \multicolumn{1}{|c|}{$\begin{array}{c}\text { Media } \\
\text { (Medium) }\end{array}$} & \multicolumn{2}{c|}{$\begin{array}{c}\text { Tingkat naungan } \\
\text { Shading level) }\end{array}$} \\
\cline { 2 - 4 } & $\begin{array}{c}\text { Tanpa naungan } \\
\text { (without shading) }\end{array}$ & $40 \%$ & $70 \%$ \\
\hline $\begin{array}{l}\text { Tanah } \\
\text { (Soil) }\end{array}$ & 32,8 & 94,0 & 61,0 \\
\hline $\begin{array}{l}\text { Sabut Kelapa } \\
\text { (Coconut husk) }\end{array}$ & 19,0 & 90,0 & 54,0 \\
\hline $\begin{array}{l}\text { Arang sekam padi+sabut kelapa =1:1 } \\
\text { (Rice husk + coconut husk) }\end{array}$ & 10,0 & 86,0 & 70,0 \\
\hline $\begin{array}{l}\text { Tanah+sabut kelapa =1:1 } \\
\text { (Soil + coconut husk) }\end{array}$ & 34,0 & 89,0 & 79,0 \\
\hline $\begin{array}{l}\text { Tanah+arang sekam padi =1:1 } \\
\text { (Soil + rice husk) }\end{array}$ & 78,0 & 82,0 & 76,0 \\
\hline $\begin{array}{l}\text { Tanah+sabut kelapa+arang sekam padi }=1: 1 \\
\text { (Soil + coconut husk + rice husk) }\end{array}$ & 78,0 & 94,0 & 81,0 \\
\hline
\end{tabular}

Berdasarkan Tabel 3 dapat dilihat bahwa pada awal pertumbuhan (umur 1 bulan) persen hidup bibit berkisar antara $57 \%$ - 97\%. Pada umur 5 bulan, persen hidup bibit suren telah mengalami penurunan hingga mencapai antara 10\% - 94\%. Penurunan rata-rata persen hidup tertinggi ditunjukkan oleh kombinasi perlakuan $\mathrm{A}_{3} \mathrm{~B}_{1}$ (arang sekam padi + sabut kelapa $(1: 1)$ pada naungan $0 \%$ ) yaitu $66 \%$ pada umur 1 bulan turun menjadi $10 \%$ pada umur 5 bulan, sedangkan penurunan persen hidup yang tidak terlalu ekstrim ditunjukkan oleh perlakuan $\mathrm{A}_{6} \mathrm{~B}_{2}(\tan a h+$ arang sekam padi + sabut kelapa (1:1:1) pada naungan $40 \%$ ) yaitu $97 \%$ pada umur 1 bulan hanya turun menjadi $94 \%$ pada akhir periode pengamatan ( 5 bulan).

Hasil analisis keragaman pengaruh media dan naungan terhadap persen hidup bibit suren umur 5 bulan (Lampiran 1) menunjukkan bahwa perbedaan media, naungan serta kombinasi media dan naungan menunjukkan pengaruh yang nyata pada taraf $1 \%$.

Hasil uji beda nyata Duncan pengaruh media dan naungan terhadap persen hidup bibit suren umur 5 bulan (Lampiran 3) menunjukkan bahwa bibit yang ditanam dalam media tanah + sabut kelapa + arang sekam padi $(1: 1: 1)\left(\mathrm{A}_{6}\right)$ pada naungan $40 \%\left(\mathrm{~A}_{6} \mathrm{~B}_{1}\right)$ dan media tanah pada naungan $40 \%$ memiliki persen hidup terbaik (94\%), meskipun demikian perlakuan tersebut tidak berbeda nyata dengan sembilan perlakuan lainnya. Sedangkan perlakuan media sabut kelapa + arang sekam padi (1:1) pada naungan $0 \%\left(\mathrm{~A}_{3} \mathrm{~B}_{1}\right)$ memiliki persen hidup bibit terendah $(10 \%)$.

\section{Indeks Mutu Bibit}

Hasil analisis keragaman pengaruh media dan naungan terhadap indeks mutu bibit suren umur 5 bulan (Lampiran 1) menunjukkan bahwa perbedaan media menunjukkan pengaruh yang nyata pada taraf $1 \%$, sedangkan naungan serta kombinasi media dan naungan tidak menunjukkan pengaruh yang nyata.

Hasil uji beda nyata Duncan pengaruh media terhadap indeks mutu bibit suren (Lampiran 2) menunjukkan bahwa media tanah + arang sekam padi $(1: 1)\left(\mathrm{A}_{5}\right)$ memiliki rata-rata indeks mutu bibit terbaik $(0,13)$ yang tidak berbeda nyata dengan media tanah $\left(\mathrm{A}_{1}\right)(0,11)$ dan media tanah + sabutkelapa + arang sekam padi $(1: 1: 1)\left(\mathrm{A}_{6}\right)(0,09)$. 


\section{B. Pembahasan}

Hasil analisa keragaman yang dilakukan (Lampiran 1) menunjukkan bahwa secara umum perbedaan media, naungan serta kombinasi media dan naungan berpengaruh nyata terhadap masing-masing parameter yang diamati, kecuali perbedaan naungan tidak berpengaruh nyata terhadap tinggi, diameter dan indeks mutu bibit suren umur 5 bulan. Selain itu kombinasi media dan naungan tidak berpengaruh nyata terhadap indeks mutu bibit suren umur 5 bulan.

Dari uji beda nyata Duncan pengaruh media dan naungan terhadap pertumbuhan bibit suren umur 5 bulan dapat dilihat bahwa perlakuan $\mathrm{A}_{6} \mathrm{~B}_{2}$ (tanah + sabut kelapa + arang sekam padi $(1: 1: 1)$ pada naungan $40 \%)$ memberikan perbedaan yang nyata pada parameter tinggi, diameter, persen hidup bibit dan indeks mutu bibit dibandingkan perlakuan lainnya. Hasil ini menunjukkan bahwa media $\mathrm{A}_{6}$ $(\operatorname{tanah}+$ sabut kelapa + arang sekam padi $(1: 1: 1))$ mempunyai hara yang dibutuhkan untuk pertumbuhan bibit suren.

Analisa tanah yang dilakukan terhadap seluruh media yang dicobakan (Lampiran 4) menunjukkan bahwa media tanah + sabut kelapa + arang sekam padi $\left(\mathrm{A}_{6}\right)$ memiliki tekstur yang cukup baik dimana perbandingan pasir : debu : liat sebesar $33: 56: 1 \%$, sedangkan standar rasio pasir, debu dan liat adalah $30: 30: 30 \%$. Kondisi ini dapat membantu pergerakan air dan udara dalam media menjadi lebih baik. Derajat kemasaman media $\mathrm{A}_{6}$ adalah masam ( $\left.\mathrm{pH} 5,8\right)$ dengan Kapasitas Tukar Kation (KTK) sangat tinggi (43,33 me/ 100 gr) dan kejenuhan basa (KB) sedang $(42 \%)$. Kondisi ini akan mempengaruhi penyerapan unsur hara oleh tanaman.

Kandungan bahan organik $\mathrm{C}$ dalam media tanah + sabut kelapa + arang sekam padi $\left(\mathrm{A}_{6}\right)$ cukup tinggi $(4,69 \%)$ dan $\mathrm{N}$ sedang $(0.34 \%)$. Perbandingan $\mathrm{C} / \mathrm{N}$ sedang (12), yang menunjukkan bahwa bahan organik dalam media $\mathrm{A}_{6}$ belum matang. Kandungan $\mathrm{P}$ dan $\mathrm{K}$ dalam media $\mathrm{A}_{6}$ sangat tinggi, yaitu $136 \mathrm{mg} / 100 \mathrm{gr}$ dan $78 \mathrm{mg} / 100$ gr. Kondisi ini mendorong pembentukan energi yang sangat aktif dalam metabolisme tanaman.

Naungan $40 \%$ memberikan pengaruh yang nyata terhadap pertumbuhan bibit suren berumur 5 bulan. Hal tersebut menunjukkan bahwa dalam pertumbuhannya, suren sangat memerlukan cahaya, sehingga ketika mendapatkan cahaya yang cukup untuk aktivitas fisiologisnya (0$40 \%$ ), tanaman cenderung melakukan pertumbuhan ke samping (pertumbuhan diameter). Hal ini sesuai dengan pendapat Marjenah (2001), bahwa pada intensitas cahaya yang cukup tanaman cenderung memacu pertumbuhan diameternya sehingga tanaman yang tumbuh pada tempat terbuka mempunyai tendensi untuk menjadi pendek dan kekar.

Perhitungan indeks mutu bibit menunjukkan bahwa perlakuan $\mathrm{A}_{6} \mathrm{~B}_{2}$ (tanah + sabut kelapa + arang sekam padi (1:1:1) pada naungan 40\%) memiliki nilai indeks mutu 0,12. Hal ini menunjukkan bahwa bibit hasil perlakuan $\mathrm{A}_{6} \mathrm{~B}_{2}$ telah siap untuk ditanam di lapangan, karena nilai indeks mutu lebih dari 0,09 akan memiliki daya hidup yang tinggi di lapangan.

\section{KESIMPULAN}

1. Media campuran antara tanah + sabut kelapa + arang sekam padi (1:1:1) memberikan pertumbuhan terbaik pada bibit suren umur 5 bulan dalam parameter tinggi $(25,1 \mathrm{~cm})$, diameter $(2,97 \mathrm{~mm})$, persen hidup $(94,0 \%)$ dan Indeks Mutu Bibit ( 0,12).

2. Jenis suren memerlukan naungan $40 \%$ pada waktu muda.

\section{DAFTAR PUSTAKA}

Alrasyid, H., Sumarhani, dan Y. Heryati. 2000. Percobaan Penanaman Padi Gogo di bawah Tegakan Hutan Tanaman Acacia mangium di BKPH Parung Panjang, Jawa Barat. Buletin Penelitian Hutan. No. 621. Hal. 27-54.

Balai Penelitian Tanah. 2006. Hasil Analisis Contoh Tanah Permintaan Balai Teknologi Perbenihan Kehutanan. Laboratorium Penelitian Kimia dan Uji Tanah. Balai Penelitian Tanah. Bogor.

Durahim dan Hendromono. 2001. Kemungkinan Penggunaan Limbah Organik Sabut Kelapa Sawit dan Sekam Padi sebagai Campuran Top Soil untuk Media Pertumbuhan Bibit Mahoni (Swietenia macrophylla King). Buletin Penelitian Hutan no. 628. Hal.13-26. 
Hendromono. 1994. Pengaruh Media Organik dan Tanah Mineral terhadap Mutu Bibit Pterygota alata Roxb. Buletin Penelitian Hutan No. 617 : 55-64.

Hendromono dan Durahim. 2004. Pemanfaatan Limbah Sabut Kelapa Sawit dan Sekam Padi sebagai Medium Pertumbuhan Bibit Mahoni Afrika (Khaya anthoteca C.DC). Buletin Penelitian Hutan No. 644. Badan Litbang Kehutanan. Puslitbang Hutan dan Konservasi Alam. Bogor.
Marjenah. 2001. Pengaruh Perbedaan Naungan di Persemaian terhadap Pertumbuhan dan Respon Morfologi Dua Jenis Semai Meranti. Jurnal Ilmiah Kehutanan "Rimba Kalimantan" Vol. 6 No. 2. Universitas Mulawarman Samarinda.

Sastrawinata, H.A. 1984. Pengaruh Intensitas Cahaya Matahari terhadap Pertumbuhan Bibit Shorea laevis RIDL. di Komplek Wanariset, Kalimantan Timur. Laporan Puslitbang Hutan No. 461. Hal. 27-54. 